\title{
Indoor concentrations of VOCs and ozone in two cities of Northern Europe during the summer period
}

\author{
J. G. Bartzis ${ }^{1}$, S. Michaelidou ${ }^{2}$, D. Missia ${ }^{1}$, E. Tolis ${ }^{1}$, D. Saraga ${ }^{4}$, \\ E. Demetriou-Georgiou ${ }^{2}$, D. Kotzias ${ }^{3}$ \& J. M. Barero-Moreno ${ }^{3}$ \\ ${ }^{1}$ University of West Macedonia, Greece \\ ${ }^{2}$ State General Laboratory, Cyprus \\ ${ }^{3}$ Institute for Health and Consumer Protection, JRC, Italy \\ ${ }^{4}$ Environment Research Laboratory, NCSR "DEMOKRITOS”, Greece
}

\begin{abstract}
Major sources of indoor organic compounds are, commonly, building materials including vinyl tiles and coverings, carpets, wood based panels, paints etc. in new or recently renovated buildings as well as human activities indoors such as cleaning or cooking. Ozone, which has both indoor (photocopiers and other) and outdoor (due to ventilation and infiltration systems) sources, is a highly reactive oxidizing agent. This study was conducted in the frame of the BUMA project (Prioritization of Building Materials Emissions). Herein is presented one week's indoor and outdoor VOCs and ozone concentration measurements from field campaigns at two urban cities in Northern Europe, Dublin and Copenhagen, during a cold period. Sampling was conducted inside and outside four buildings. The concentrations of hazardous compounds (formaldehyde, benzene, acetaldehyde, toluene and xylenes) ranged from 5.9-42.7, 0.6-3.4, 2.3-41.6, $2.2-15$ and $0.4-6 \mu \mathrm{g} / \mathrm{m}^{3}$, respectively. Ozone levels were significantly higher outdoors that indoors.
\end{abstract}

Keywords: indoor air quality, VOCs, formaldehyde, ozone, passive sampling.

\section{Introduction}

Human activity studies have shown that people spend on average more than $85 \%$ of their time inside buildings. This proportion can be analysed more specifically 
as $66 \%$ in residential buildings and another $5 \%$ inside vehicles [1]. In recent years, extensive research effort has been invested in examining the relationship between indoor air quality and the application of building materials in new or recently renovated buildings. A variety of studies have demonstrated that building materials with large surfaces are meaningful emission sources of organic compounds and influence the concentration levels in indoor environments. Temporary pollution events such as painting, cleaning, cooking or smoking can contribute to indoor air quality even after the the application has stopped. Sakr et al [2] pointed out that even building materials and the installation of new furnishings that are designed to have low emissions can play a significant role in polluting the indoor environment through sorption and subsequent desorption of pollutants.

Building materials and human activities indoors are major sources of Volatile Organic Compound (VOC) emissions. VOCs have both indoor and outdoor sources and they are of particular interest due to their potential impact on human health [3]. Formaldehyde and benzene, for example, are considered the most studied pollutants since they are classified in Group 1 of human carcinogens by the International Agency for Research on Cancer because of their carcinogenicity [4]. On the other hand, ozone also has both indoor (photocopiers and other office equipment) and outdoor (due to ventilation processes) sources in indoor environments. Ozone can easily react with terpenes and other organic compounds forming ultrafine particles and irritating gaseous organic compounds [5].

For many of these chemicals, the risk on human health and comfort is almost unknown and difficult to predict because of the lack of toxicological data. In the framework of the INDEX project the existing knowledge worldwide has been assessed on type and levels of chemicals in indoor air as well as the available toxicological information. Thus, the INDEX project concluded in a priority ranking of 14 chemicals assigned to three groups [6].

The present work was conducted in the framework of the BUMA project (Prioritization of Building Materials Emissions) and aims to thoroughly assess the human exposure to air hazards emitted from building materials. This study focuses on compounds belonging to the first two priority groups of the INDEX project such as benzene, toluene, xylenes, formaldehyde and acetaldehyde.

\section{Materials and methods}

\subsection{Campaign organization}

This study was carried out in 2007 from 28 of May to 3 of June and 24 of June to 1 of July for Dublin and Copenhagen, respectively. Measurements were conducted in four buildings in order to evaluate the indoor air VOCs and ozone. The study design included the selection of the buildings in which passive samplers were installed. The buildings employed in the present study were selected according to the following criteria: (1) the age (less than two years), (2) the last reconstruction or renovation and (3) the position of the building (urban 
sites were preferred). There are four buildings in every case, one public building, one school and two private houses. In addition, temperature and relative humidity (RH) data loggers were used inside the tested rooms. Finally, the tracer gas technique was used for ventilation measurements, where it was possible.

Moreover, questionnaires were filled in, giving valuable information regarding sampling sites and activities taken place during sampling. At indoor locations, the passive sampling equipment was placed on sites on the wall approximately $1.5 \mathrm{~m}$ above the ground, or on tables or other furniture, wherever possible. Outdoor sampling locations were chosen to avoid significant point sources of pollution, such as building exhaust vents.

\subsection{Sampling and analysis}

Indoor and outdoor measurements of BTEX, carbonyls and ozone were conducted using passive samplers named Radiello in each tested room and outside for one week. The samplers used for BTEX were Activated Charcoal Cartridges $\left(\mathrm{CS}_{2}\right.$-desorption) for GC-analysis (code 130), for Aldehydes DNPHcovered cartridges (acetonitrile desorption) for HPLC-VIS (code 165) and for ozone 1, 2- di- (4-pyridyl) ethylene covered cartridges (MBTH (3-Methyl - 2Benzothiazolinone Hydrazone) solution desorption), for UV-VIS (code 172).

The analysis of BTEX was carried out by GC/FID after desorption of the analytes with $\mathrm{CS}_{2}$ and included determination of benzene, toluene, xylenes, ethylbenzene, 1,2,4 trimethylbenzene, d-limonene and a-pinene. The determination of all analytes was confirmed by GC-MS. The analysis of carbonyls and ketones was carried out using HPLC-VIS after desorption of the analytes with acetonitrile and included determination of formaldehyde, acetaldehyde, acetone, propanal and hexanal. Finally, the analysis of ozone was conducted using spectrophotometer-VIS after desorption with (MBTH) solution. The analysis of the samples was conducted in the State General Laboratory (SGL) of Cyprus.

With tracer gas technique, air exchange rates were estimated, only for Dublin's office building, using NORDTEST METHOD NT VVS 118. This method can be used in types of buildings, dwellings, offices, schools etc. The testing of ventilation is performed by using homogeneous emission of tracer gas at a constant rate in the ventilated system and subsequent analysis of the steady state concentration of that tracer gas in different parts of the system [7].

\section{Results and discussion}

\subsection{Volatile Organic Compounds (VOCs)}

Summary statistics for the concentrations of all measured compounds in indoor air are given in table 1. The most prevalent VOCs in buildings were formaldehyde, acetaldehyde, acetone, hexanaldehyde and a-pinene. Indoor concentrations usually exceeded outdoor levels. High priority compounds constituted large proportion of sum of VOCs in both cities' schools, fig. 1, lower 
than those reported in Michigan classrooms by Godwin et al [8]. Formaldehyde in Copenhagen school exhibited the same levels observed in schools at Porto [9] and in Shangai, China [10].

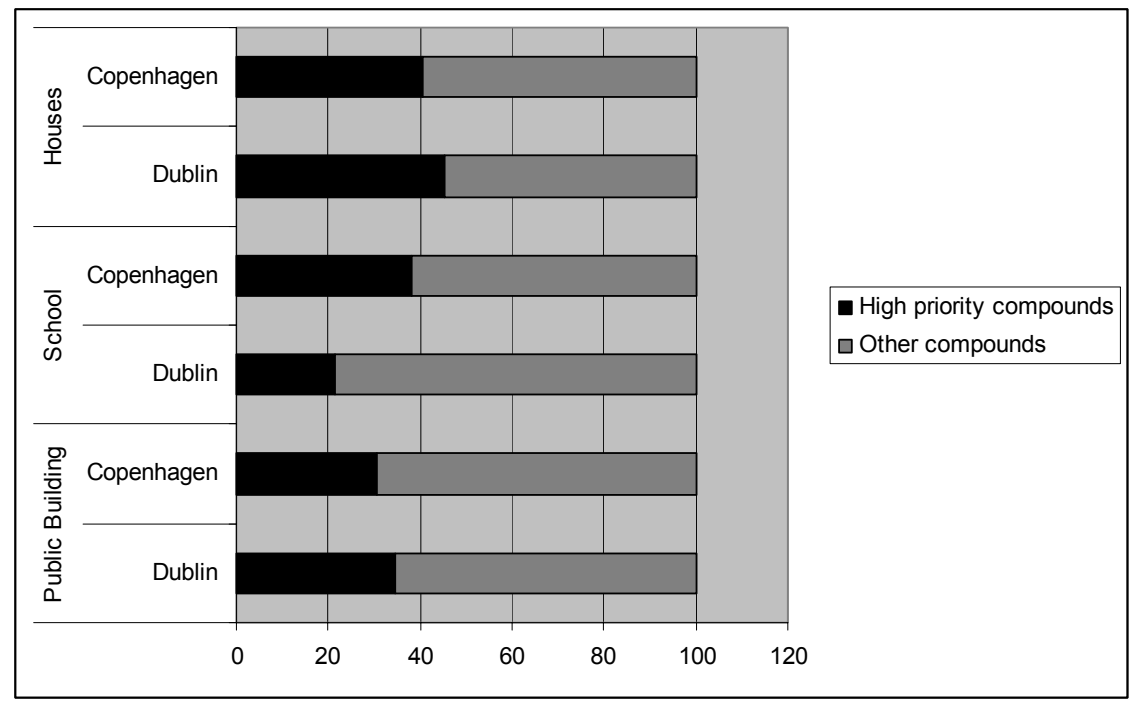

Figure 1: Average percentage of sums of high priority compounds in selected buildings.

Reported public buildings' indoor concentrations of individual VOCs are generally below $50 \mu \mathrm{g} / \mathrm{m}^{3}$. Levels of aldehydes in Dublin's office building are lower than those observed in Copenhagen except for formaldehyde. Mean concentrations of the majority of VOCs in both cities are below $10 \mu \mathrm{g} / \mathrm{m}^{3}$, a common trend for both European and American countries [11]. Low concentrations of VOCs in Dublin's office building can be associated with the large air flow rate, which was estimated to be $3.66 \mathrm{~h}^{-1}$.

Acetaldehyde and hexanaldehyde levels are similar to those found for private houses and dwellings in Paris $[12,13]$. Such observations suggest probably the absence of indoor sources for acetaldehyde since acetaldehyde is mainly emitted from combustion processes. Propionaldehyde concentrations in houses were measured lower than those found in dwellings in Paris [13]. The levels of formaldehyde did not exceed the WHO guideline value of $100 \mu \mathrm{g} / \mathrm{m}^{3}$, which may cause nose and throat irritation in humans after short-term exposure [14].

It is worth to notice that concerning high priority compounds, except for benzene and toluene in some cases, indoor to outdoor ratios (I/O) are substantially greater than one (>1) suggesting important indoor sources for these VOCs. More specifically, for hexanaldehyde $\mathrm{I} / \mathrm{O}$ ratio is up to 37.8 , for acetaldehyde 26.1, for acetone 14.6, and for formaldehyde 15.3. 


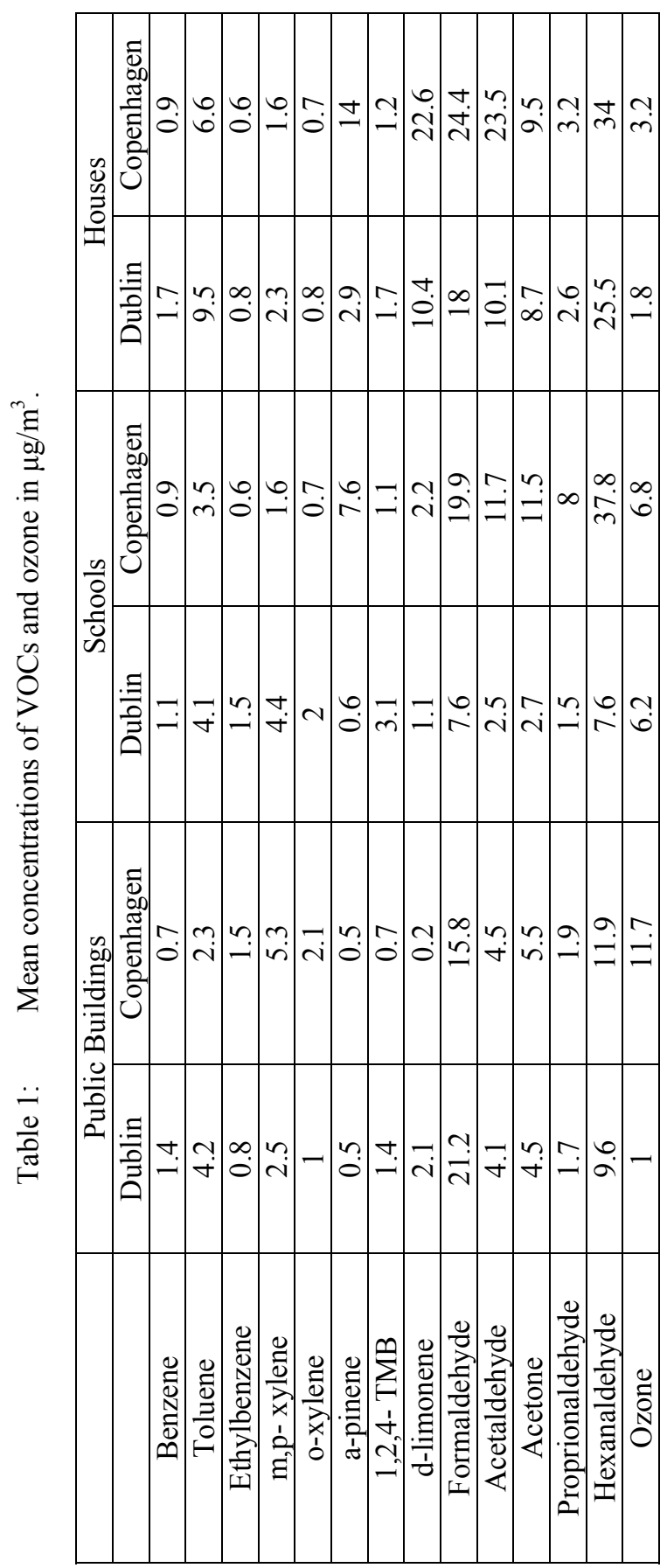




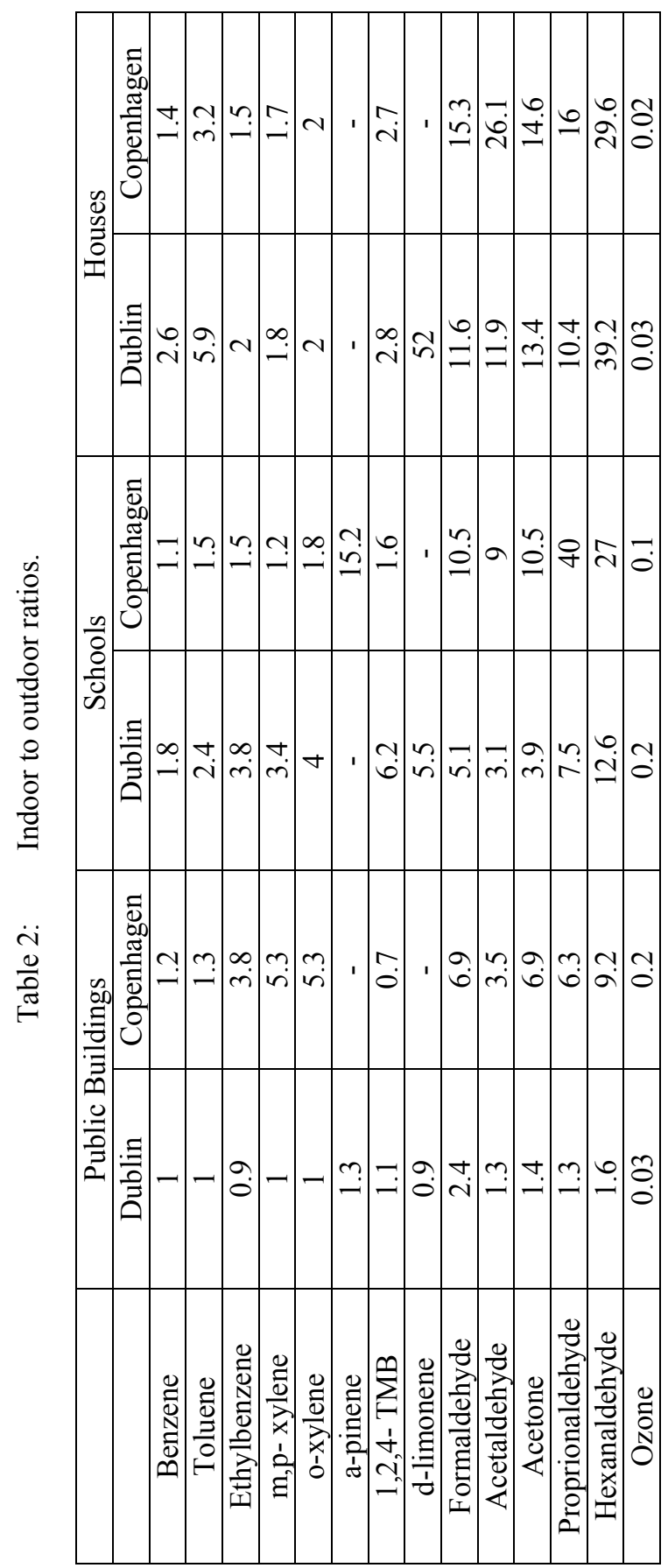




\subsection{Ozone $\left(\mathrm{O}_{3}\right)$}

The importance of measuring ozone in indoor environments comes from its ability to react with high molecular organic compounds and specifically with terpenes forming ultrafine particles and free radicals. As it is observed, outdoor concentrations are significantly higher in contrast with indoor levels. The indoor to outdoor ozone concentration ratio generally ranged between 0.03 and 0.2 indicating ozone - indoor chemistry relationship as mentioned by Nicolas et al [15].

\section{Conclusions}

The concentration data show a considerable diversity due to the different indoor emission sources, ventilation rates and outdoor environments concentrations. Aromatic compounds' levels in all buildings are lower than those expected in indoor environments. The sum of high priority compounds consist a large proportion of the TVOC in all selected buildings. The relatively high I/O ratios for carbonyls and ketones indicate strong indoor emissions sources. Ozone outdoor concentrations seem to be reduced substantially inside; indicating relatively strong indoor ozone sinks.

\section{Acknowledgement}

The BUMA project is funded by the European Community, Public Health Executive Agency (PHEA).

\section{References}

[1] Ogulei D., Hopke P.K. \& Wallace L.A., Analysis of indoor particle size distributions in an occupied townhouse using positive matrix factorization. Indoor Air, 16(3), pp. 204-215, 2006.

[2] Sakr W., Weschler C.J. \& Fanger P.O., The impact of sorption on perceived indoor air quality. Indoor Air 16(2), pp. 98-110, 2006.

[3] Marchland C., Bulliot B., Le Calve S. \& Mirable Ph., Aldehyde measurements in indoor environments in Strasbourg (France). Atmospheric Environment 40, pp. 1336-1345, 2006.

[4] IARC, Overall evaluation of Carcinogenicity to Humans, Formaldehyde [50-00-0], Monographs Series, 88, International Agency for Research on Cancer, Lyon, France.

[5] Molhave L., Kjaergaad S.K., Sigsgaard T., Lebowitz M. Interaction between ozone and airborne particulate matter in office air. Indoor Air, 15(6), p.p. 383-392, 2005.

[6] Kotzias D., Koistinen K., Kephalopoulos S., Schlitt C., Carrer C., Maroni M., Jantunen M., Cochet C., Kirchner S., Lindvall T., McLaughlin J., Mølhave L., De Oliveira Fernandes E. \& Seifert B., 'The INDEX project'" 
Critical appraisal of the setting and implementation of indoor exposure limits in the EU. Final Report. (2005)

[7] Ventilation: Flow rate, total effective - by single zone approximation. NORDTEST METHOD NT VVS 105, 1994.

[8] Godwin C., Batterman S., Indoor air quality in Michigan schools. Indoor Air, 17(2), pp. 109 - 121, 2007.

[9] Samudio M.J, Ventura Silva G., Oliveira Fernandes E., Guedes J., and Vasconcelos M.T.S.D., A Detailed Indoor Air Study in a School of Porto. Proc. of Healthy Buildings Conf. eds. E. de Oliveira Fernandes, M Gameiro da Silva, J. Rosado Pinto, pp. 345-349, 2006.

[10] Mi Y.H., Norback D., Tao J., Mi Y.L., Ferm M., Current asthma and respiratory symptoms among pupils in Shangai, China: influence of building ventilation, nitrogen dioxide, ozone and formaldehyde in classrooms. Indoor Air, 16(6), pp. 454-464, 2006.

[11] Wolkoff P., Wilkins C.K., Clausen P.A., Nielsen G.D., Organic Compounds in office environments - sensory irritation, odor, measurements and the role of reactive chemistry. Indoor Air, 17(1), pp. 7 19, 2006.

[12] Marchand C., Bulliot B., Le Calve S., Mirable Ph., Aldehyde measurements in indoor environments in Strasbourg (France). Atmospheric Environment, 40, pp. 1336-1345, 2006.

[13] Clarisse B., Laurent A.M., Seta N., Le Moullec Y., El Hasnaoui A., and Momas I., Indoor aldehydes: measurement of contamination levels and identification of their determinants in Paris dwellings. Environmental Research, 92, pp. 245-253, 2003

[14] WHO (2001). World Health Organization, Air quality guidelines for Europe 2000. WHO Regional Office for Europe.

[15] Nicolas Melanie, Ramalho Olivier, Maupetit Francois, Reactions between ozone and building products: Impact on primary and secondary emissions. Atmospheric Environment, 41, pp. 3129-3138, 2007. 